\title{
Ancient orders of nature
}

\section{Martin Kemp}

The blind giant, Orion, his left arm extended in a precautionary manner, proceeds along a road in a sumptuous landscape. He is guided by his companion, Cedalion, who stands on his shoulders and directs him towards the rising Sun, prescribed as a cure for his sightless condition.

Orion had been blinded in Chios by the father of Princess Merope, whom he had vilely attempted to rape. The goddess Diana coolly observes Orion's uncertain progress from the cluster of clouds that still veil the giant's head from the restorative Sun. It was Diana who later translated the giant into the starry constellation, after Orion had unwisely directed his rapacious intentions towards her.

Even if the subject of the blind Orion was very rare, we are familiar enough with this kind of picture from the Renaissance and Baroque eras. The Landscape with Blind Orion Searching for the Sun (pictured) was painted in 1658 by Nicolas Poussin, the French artist resident in Rome during the last years of his life.

Like a number of paintings on ancient themes, it was inspired by an account of a lost work by an ancient author. Lucian, in The Hall, describes a sequence of wall paintings: "The next picture deals with the ancient story of Orion. He is blind, and on his shoulder carries Cedalion, who directs the sightless eyes towards the East. The rising Sun heals his infirmity."

Beyond the highly controlled naturalism, there is little to suggest that either the subject or the artist might be engaged with the scientific culture of the time. However, as Ernst Gombrich showed in 1994,
Poussin's most direct literary source was a reference book on classical mythology that aspired to demonstrate how "all the doctrines of Natural and Moral Philosophy were contained in the fables of the ancients". It was published in 1551 in Mythologiae by Natalis Comes (Natale Conti), who went to acrobatic lengths to show how ancient myths embodied modern discoveries in the guise of allegory.

Poussin, as the supreme

"philosophical painter" of his (or virtually any other) generation was naturally drawn to a source that promised to bind the wisdom of his revered 'ancients' to the new sciences. Poussin, who moved in high intellectual circles in Rome, insisted on the rational basis of art as visual knowledge.

He defined the proper role of painting as a form of rational scrutiny, distinct from mere seeing and passive imitation. It was to reveal in form and content the underlying order of the created world and the integral position of humans in the divine system of nature. The landscape is based on the wonderfully fresh studies that Poussin made directly from nature, but the landscape's naturalism is reshaped in terms of what he called "the order and the mode and the species of things".

\section{But what of the specific} interpretation of the Orion myth provided by Conti? In summary, Conti's horribly tangled 'scientific' reading runs as follows. Improbably born of the triple copulation of Jupiter, Neptune and Apollo with the hide of oxen, Orion was accordingly composed of air, water and fire, as expressed as wind, rain and thunder. Orion's journey to Chios, his rape of - in Conti's version - Aerope (air) and blinding signify the diffusion of his watery powers in the form of vapours, which rise impotently into the upper atmosphere. The ascending vapours are gathered by the cold power of the Moon (Diana) to be cast Earthwards as rainstorms. Conti concludes the story represents the "cyclical and mutual generation and destruction of the elements".

Conti's musings have long been abandoned. Poussin's painting, on the other hand, continues to breathe a timeless sense of the inherent grandeur of nature stirring with inner life and cyclical renewal. Like Cedalion, Poussin saw himself standing on the shoulders of both the giants of antiquity and of his own time, to see further into the truths of the created world.

Martin Kemp is research professor in the history of art at the University of Oxford, Oxford OX11PT, UK.

Poussin and Nature: Arcadian Visions runs 12 February-11 May at New York City's Metropolitan Museum of Art.

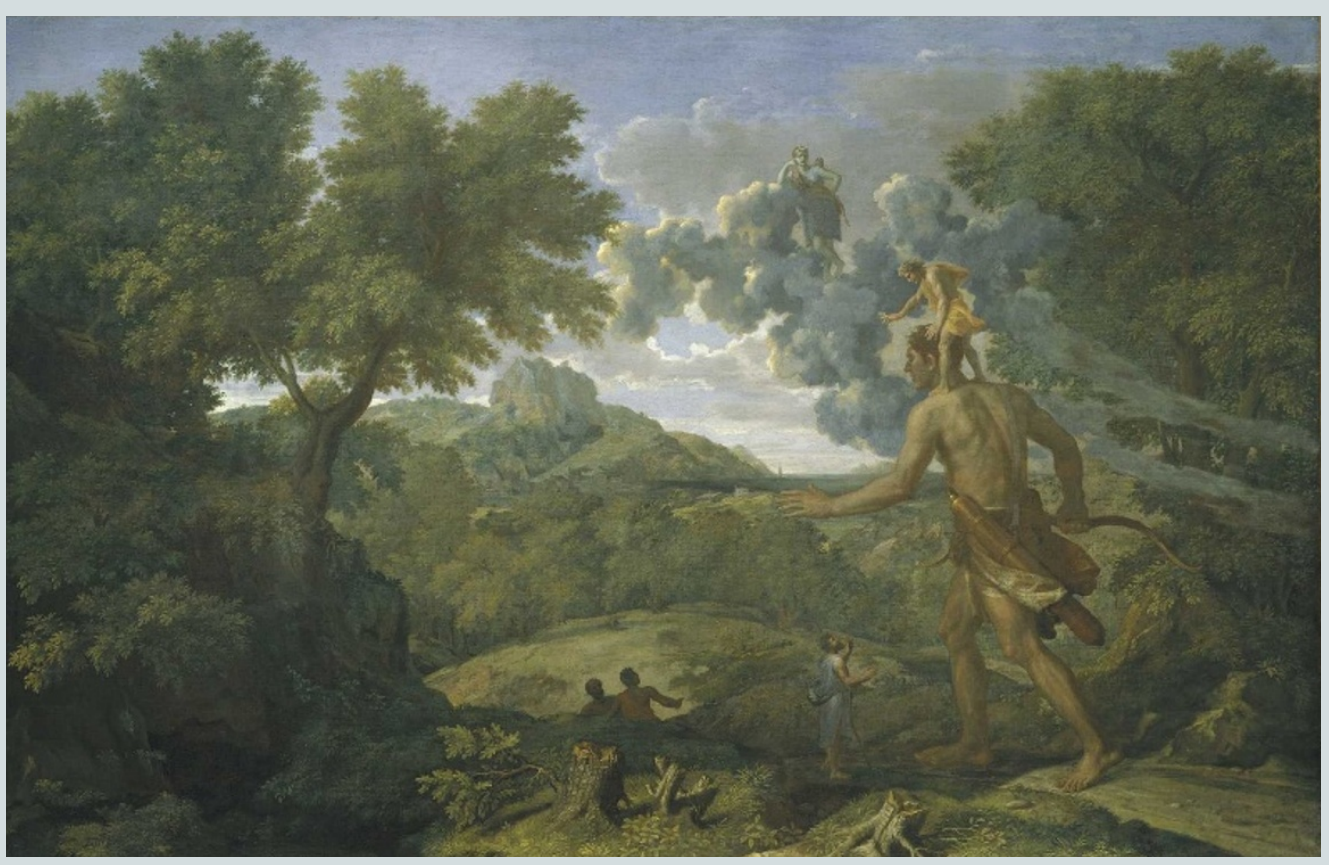

focused and tightly argued, it excludes a few peripheral topics. One wonders why Vernon chose not to explore the evolution of British diets in Victorian times. Sugar-sweetened tea, bread-and-jam and "sugar butties" were adaptations by the poor to industrial employment that alleviated hunger cheaply but also created malnutrition. More curious is the omission of the improvement in stature and life expectancy that started with the repeal of the Corn Laws. The importance of journalism in raising consciousness of hunger as a social problem is discussed, but less emphasis placed on writers such as Dick- ens, Elizabeth Gaskell and Henry Mayhew. The attitude of the Church is also neglected.

Vernon's story ends in the 1940s when many newly independent nations took responsibility for huge populations. Destitute on a scale never seen in Europe, they faced an accelerated birth rate if the food supply improved. Severe famines have occurred and have been blamed on poor economic management and distribution rather than Malthus' prophecy of moral punishment. Malnutrition is a more insidious problem. In the developing world, vast numbers of people are deficient in vitamins and micro- nutrients because the range and volume of their food intake is minimal. Consequences include stunted growth of children, low birth weight, decreased immunity to infection and damaged eyesight. Although appropriate welfare schemes can be devised, the solution may lie ultimately in increased economic prosperity. There is little doubt that when incomes improve, the quality of food intake improves.

Michael Sargent is a developmental biologist based at the National Institute for Medical Research, Mill Hill, NW7 1AA, UK. He is the author of Biomedicine and the Human Condition. 